\title{
Measuring the Efficiency of Public Hospitals in Saudi Arabia Using the Data Envelopment Analysis Approach
}

\author{
Mansour Abdullah Almiman \\ ${ }^{1}$ Associate Professor of Management in Jeddah College of Technology, Jeddah, Saudí Arabia \\ Correspondence: Mansour Abdullah Almiman, Associate Professor of Management in Jeddah College of \\ Technology, Jeddah, Saudí Arabia. E-mail: morganiteinstitute@yahoo.com
}

\author{
Received: February 12, 2018 \\ Accepted: August 25, $2018 \quad$ Online Published: November 13, 2018 \\ doi:10.5539/ijbm.v13n12p111 \\ URL: https://doi.org/10.5539/ijbm.v13n12p111
}

\begin{abstract}
This purpose of this paper is to measure technical and scale efficiencies of public hospitals in 20 regions in Saudi Arabia. Furthermore, these estimates and the slack-based forecasting and the sensitivity analysis of the stability of efficiency scores were calculated. The researcher used Data Envelopment Analysis (DEA) technique based on two models - CCR and BCC, with an input-oriented approach. The Ministry of Health in Saudi Arabia published the Health Statistical Year Book for the years, 2010, 2011, 2013, 2014 and 2015 from which the data were obtained. The variables chosen included the number of beds, staff nurses and doctors as inputs, and outpatients, inpatients and surgeries representing outputs. Results indicate that the BCC model tends to classify more regions as efficient. The average PTE score of inefficient hospitals was 88 percent over the period in question, which implies that inputs could be reduced by 12 per cent without it impacting in any way on the service provided. Hospital managers and policy makers will thus play a critical role in ensuring that resources are utilised to their full potential in order to optimise efficiency. The inefficient regions could make their hospitals efficient by following the efficient regions as peers. Finally, it was found that there is stability in the efficiency scores of hospitals as revealed by sensitivity analysis, even when taking into account the exclusion of the most efficient hospitals.
\end{abstract}

Keywords: Data envelopment analysis, technical efficiency, scale efficiency, sensitivity analysis, region hospitals

\section{Introduction}

Saudi Arabia spends a considerable percentage on health care from its national income, this spending is rising. In 2010, health care spending represented 6.5 percent of the total government budget and in 2015 it reached a high of 7.25 percent. Total health expenditures rose from SR 35063 million in 2010 to SR 62342 million in 2015, i.e., marking a 78 percent increase (Health Statistical Year Book, 2015). A large proportion of the expenditure was spent on public hospital services, accounting for 68 percent of total health expenditure in 2105 .

The Ministry of Health $(\mathrm{MOH})$ in Saudi Arabia is the main provider of public care and it governed the health care system. The Saudi government funds health care both directly and indirectly through subsidies to private hospitals and centres. The Ministry of Health supervises 274 public hospitals scattered all over the country. The average size of these hospitals is approximately 151 beds, with a range of $200-7937$ beds (Health Statistical Year Book, 2015). It should be noted that 19 percent of public hospitals and 17 percent of public beds are located within the region of Riyadh.

Despite this increase in health services, Saudis seeking treatment in public hospitals find that there are a huge number of patients being refused immediate treatment, which leads to the general perception in Saudi Arabia of inefficient health care supply. The technical inefficiency is sometimes associated with the high level of spending on hospital services. This led to a surge in interest in measuring the efficiency of Saudi public hospitals to provide a useful framework for improving their efficiency and ensuring that all resources are utilised to their full extent. Therefore, identifying the best manner in assigning capitals is done by the efficiency analysis. Technical efficiency describes the relationship between output and the quantity of resources used to produce that output.

\subsection{Significance of the Study}

This study is motivated by the current lack of empirical evidence in the literature regarding measurement of 
technical efficiency of the health care system in Saudi Arabia. Taking into account the outcome of this study, health care decision-makers can tailor their policies in order to utilise their existing resources more efficiently. Understanding the cost structure of hospitals and their effectiveness in utilising resources is crucial for making health care policies and budgeting decisions. Hospitals operating at a higher level of efficiency are likely to help control the use of resources, which ultimately will assist in providing a more robust and effective service to the public.

\subsection{Purpose of the Study}

The purpose of this study is to measure technical and scale efficiencies of public hospitals in 20 regions in Saudi Arabia.

\subsection{Study Hypothesis}

Hospitals in Saudi Arabia have pure technical efficiency

\section{Literature Review}

DEA has been extensively applied in the international literature to assess the efficiency of hospitals.

Several studies have used a DEA model to study the efficiency of hospitals within the United States. For example, Burgess and Wilson (1998), Grosskopf and Valdmanis (1987, 1993) and Valdmanis (1992), among others, use DEA to compare the efficiency of United States' hospitals in accordance with their ownership type. Numerous researchers such as Brown and Pagán (2006), Harrison and Sexton (2006) and Harrison, Coppola and Wakefield (2004) analysed hospitals nationwide in the 1990s using input-based DEA, yielding efficiency scores of 0.68 to 0.79 . In 2002, Ferrier, Rosko and Valdmanis (2006) studied 170 hospitals in the state of Pennsylvania using output-oriented DEA and determined that technical inefficiency was the major component responsible for the failure to reach maximum potential. The study by Chen, Hwang and Shao (2005) concluded that there was a declining trend in overall technical efficiency for 89 acute care hospitals in California for the period 1992-97 and the fall in efficiency was caused entirely by a decline in pure technical efficiency. Moreover, DEA has been applied to study efficiency in nursing homes, pharmacies and at the physician level. Hollingsworth, Dawson and Maniadkis (1999) together with Worthington (2004) provide comprehensive reviews of the literature on efficiency measurement in the health care sector using nonparametric methods. A study conducted by Chilingerian and Sherman (2004) focused on the history of health care applications of DEA and analysis of various issues involved when applying DEA for efficiency measurement in the health care sector.

Hollingsworth $(2003,2008)$ and Worthington (2004) carried out investigative studies with the use of DEA in order to determine the level of effectiveness within European Hospitals and DEA-based efficiency studies were undertaken by O'Neill, Rauner, Heidenberger and Karus (2008) and Emrouznejad, Parker and Tavares (2008). These studies taken together yielded an extensive efficiency baseline going back several decades. A recent study was conducted by Asandului, Roman and Fatulescu (2014), whereby the efficacy of European public healthcare systems were evaluated by implementing data envelopment analysis. In doing so, they applied statistical data covering 30 European states for the year 2010. Life expectancy at birth, health-adjusted life expectancy and infant mortality rate were the three output variables taken into consideration, whilst the input variables took the form of the number of doctors, number of hospital beds and public health expenditures as a percentage of GDP. The results revealed that there are a number of both developed and developing countries providing an efficient and robust service, whilst the majority of countries flounder and struggle to attain the required level of efficiency.

In developing countries, Umakant, Vaishnavi, Muraleedharan and Debashis (2007) applied DEA to quantify and study the efficiency of all the 29 district hospitals in the state of Tamil Nadu. They introduced four input variables: numbers of assistant surgeons, civil surgeons, staff nurses and beds, and four output variables: in-patient and outpatient visits, major and minor surgeries, and deliveries performed. The study was based on the input-oriented model and took into consideration variable returns to scale, with units being ranked according to a guiding principle. The results showed that eight of the 29 hospitals were efficient, exposing the remaining 21 hospitals to be inefficient, needing to considerably raise their game in order to be on a par with that of their peer group.

Recently, Prakash and Annapoorni (2015) carried out a detailed study that covered 31 district hospitals in the state of Tamil Nadu and gave estimates of technical efficiency. They used seven variables in the model. The following three variables were chosen as inputs: number of beds, staff nurses and assistant surgeons/civil surgeons. The following three variables were chosen as outputs: outpatients treated, major surgeries and total deliveries performed. An output-oriented model was utilised for calculating DEA, allowing variable return to 
scale (VRS) and units were marked according to the benchmarking model. The results revealed that nine of the 31 hospitals were being run efficiently, while the remaining 22 were relatively inefficient, and needed to improve their performance in line with that of their peer group.

In the state of Kedah, Malaysia, Applanaidu et al (2014) applied DEA to examine technical and scale efficiencies of nine district public hospitals within the period 2008-2010. Using the pooled data technique, they were able to provide a set of 27 decision-making units (DMUs). The number of doctors, nurses and beds accounted for input variables, with output variables consisting of the number of outpatients, inpatients, surgeries and deliveries performed. Results indicate that 20 DMUs were technically efficient placing them on the best practice efficient frontier while the remaining 4 hospitals lagged behind with an efficiency score of 0.938 .

Tigga and Mishra (2015) assessed and compared technical efficiency of the health system across 27 states in India. They applied the output-oriented DEA model which was based on a variable return to scale (VRS). The input variables considered for the study were health workers (doctors, nurses and paramedical staff) and health centres whereas the output variables were infant survival rates and percentage of institutional deliveries. Their results indicated that six of the 27 states were efficient, while the remaining 21 states were relatively inefficient, using more than the required amount of inputs to achieve the current levels of output. It was deduced that their efficiency levels could be improved by following the lead of their peers.

Mogha et al (2012) applied DEA-based CCR and BCC models to evaluate the relative efficiency performance of 55 private sector hospitals in India for the periods 2009-2010. The study employs three input measures: net fixed assets, energy expenses, wages and salaries, whilst the operating income is taken as an output measure. The study presents that ten hospitals were efficient, while the remaining 45 states were relatively inefficient. Slack analysis was also used to assess the quantity of excess resources used and/or deficient output produced. The results indicate the scope for improvement in fixed capital utilisation. The sensitivity analysis represents that the efficiency scores of the hospitals are stable even after the exclusion of the top performer.

Using DEA, Gok and Sezen (2011) obtained an estimate of the technical efficiencies relating to Turkish hospitals regarding their ownerships for the years 2001 to 2006. By adopting DEA, they noted that when comparing the average efficiencies of state hospitals with private hospitals, it was evident that the former increased whilst interestingly, the latter decreased, moreso since the implementation of reforms in state-owned hospitals. The study used three input variables and ten output variables.

Shahhoseini et al (2011) made an attempt to measure technical efficiency of 12 provincial hospitals (public and private) in Iran for the year 2008. The DEA model was based on four inputs: number of physicians, nurses and other staff, and number of active beds within the hospital; the five outputs consisted of: inpatient bed days, average length of stay, bed occupancy rate, outpatient visits and number of operations. The study applied both CRS and VRS to compute the efficiency performance of the hospitals. The results revealed that just under 60 percent of all hospitals were technically efficient, whilst the remainder failed to make the grade as a result of overuse of inputs, requiring serious attention from the managers in order to address the situation.

Studies on DEA in Saudi Arabia in general, and in the health care sector in that country in particular, are disappointingly quite limited. Abou El-Seoud (2013) investigated the efficiency performance on a sample of 20 public hospitals that have been reformed to operate under private sector management through the full operating system for 2011. Efficiency measures are based on four resource input measures including: number of specialists, number of nurses, number of allied health and number of beds, and also four output variable measures: number of out-patient visits, number of patient admissions to hospital, number of laboratory tests and number of beneficiaries of radiological imaging. The study used both CCR and BCC. Only 40 percent of the hospitals studied proved to be operating efficiently. Al-Shayea (2011) used a DEA model to measure the relative efficiency performance of 9 units delivering similar services at King Khalid University Hospital over a period of 12 months in 2010. Two input measures and three output measures were selected to measure the efficiency for each department. The input measures are the total salary for doctors and the total salary for nurses, whereas the output measures are the number of in-patients and out-patients, bed productivity and average turnover interval. The results showed that only two departments out of nine were running in an organised and streamlined fashion within the time period of the study.

\section{Methodology}

This study uses a DEA approach to ascertain the technical efficiency of public hospitals operating in 20 regions in Saudi Arabia. DEA is a non-parametric mathematical programming approach. DEA is a well-established and useful technique for measuring efficiency in public sector activities and has become an accepted methodology for evaluating efficiency, particularly in the hospital sector (O'Neill et al 2008). This is because (1) when 
constructing the production function, no specific form is required; (2) it is permissible to use both multiple-input and multiple-output analysis and (3) data on prices for technical efficiency analysis is not required. A drawback of DEA is that it does not differentiate inefficiency from random error. However, Simar and Wilson (1998) suggested a solution to this limitation by adopting a bootstrap approach in order to obtain bias-corrected DEA estimates.

The concept of DEA was first introduced by Charnes, Cooper and Rhodes (1978). This model is referred to in the literature as the CCR model, which determines the technical efficiency of the observed decision-making units (DMUs). The CCR model assumes constant returns to scale (CRS), which means that proportional increases in input results in proportional increases in output. Later, Banker, Charnes and Cooper (1984) devised a different version which took into account the variable returns to scale (VRS), which means that increases in input do not bring about a commensurate change in output. This model is known as the BCC model, which measures pure technical efficiency. Any dissimilarities that occur in efficiencies, which are estimated assuming VRS and CRS are then surmised to reflect scale efficiencies (SE). The final scores on technical efficiency indicate how productive a hospital is relative to best practice. For example, a score of one equals total efficiency and a score of less than one represents inefficiency. The values on slacks in each hospital show how much of each input can be reduced in order to reach the same level of output (Perez et al, 1988). There are other basic DEA models such as the additive model, the multiplicative model, the assurance region DEA model and the super efficiency model. However, these models are rarely used in the literature (Barros, 2005).

The DEA model is input or output oriented. An output-oriented model points to the amount of output that can be expanded proportionally with fixed inputs, whilst the input-oriented models quantify the amount of inputs that can be reduced proportionally, while holding the outputs fixed. Both these orientations represent the amount of inputs or outputs that can be changed so that a firm can attain a technical efficiency of one hundred percent to be on the frontier.

This paper assumes that the technology exhibits VRS, as assuming CRS does not hold true in a realistic situation. However, CRS efficiency scores were computed to figure out the scale efficiencies (SE) of hospitals. Scale efficiency is calculated as the ratio of the CRS to VRS technical efficiency score, with a ratio of $<1$ indicating that the size of the hospital is not proportional to its optimum size. Furthermore, we apply an input-oriented efficiency measure since hospital management has greater control over inputs than over outputs. In health care studies, most researchers have used an input oriented model because hospital management does not have control over the outputs such as discharges, patient days or number of outpatient surgeries performed (Harris et al, 2000; Kazley and Ozcan, 2009; Sikka et al, 2009).

\subsection{Data and Variables}

When determining the selection of inputs and outputs in the DEA study great care and attention must be applied, as it could influence the efficiency scores. Hospitals in Saudi Arabia as elsewhere, do not directly measure outputs such as changes in health status. Of necessity, any studies carried out relating to hospital efficiency, must rely on the intermediate to good health services in order to measure hospital output. The present study was no exception. Making reference to previous studies, especially those studies on developing countries, the present empirical analysis was designed based on the availability of data, as well as measures commonly adopted in the literature.

The Health Statistical Yearbooks for the years 2010, 2011, 2013, 2014 and 2015 provided the necessary data. Data on inputs and outputs were published at aggregate form for each region. Public Hospitals in the 20 regions are homogenous as they provide all types of care and are regulated and owned by the Ministry of Health. Hospitals were considered to transform labour and capital into health services, approximated by the number of outpatient cases (OP), number of inpatient cases (IP) and number of surgeries (SUR). The annual number of nurses (NUR), and the number of doctors (DOC) is used as a proxy for labour inputs. A hospital's capital stock was represented by the number of hospital beds (BED).

The Health Statistical Yearbooks provided a comprehensive list of inputs and outputs, which reflect the general and informative results. However, only a few inputs and outputs have been taken, as too many for a comparatively small sample may not discriminate effectively between efficient and inefficient regional hospitals. In this context, Boussofiane et al (1991) specified that to attain favourable discriminatory power from the CCR and BCC models, the lower bound on the number of DMUs should equate to the multiple of the number of inputs and outputs. Further, however, Golany and Roll (1989) established a rule of thumb advocating that the number of units should be double the number of inputs and outputs considered. This methodology was also suggested and embraced by Dyson et al (2001). Conversely, Bowlin (1998) recommended having three times the 
number of DMUs as there are input and output variables. In this paper, as a broadly accurate guide, we have 3 inputs, 3 outputs and 20 regions for each considered year of the study to ensure that our DEA models are more discriminatory.

\section{Results}

\subsection{The Input-Oriented CCR MODEL}

The CCR model for measuring the input-oriented efficiency value of a test DUM can be written as proposed by Charnes et al. (1978) as follows:

$$
\min \theta-\varepsilon\left(\sum_{i=1}^{m} s_{i}^{-}+\sum_{r=1}^{s} s_{r}^{+}\right)
$$

Subject to

$$
\begin{gathered}
\sum_{j=1}^{n} x_{i j} \lambda_{j+s_{j}^{-}}=\theta x_{i 0} i=1,2, \ldots, m ; \\
\sum_{j=1}^{n} y_{r j} \lambda_{j}-s_{r}^{+}=y_{r 0} r=1,2, \ldots, s ; \\
\lambda_{j} \geq 0 \mathrm{j}=1,2, \ldots, n .
\end{gathered}
$$

Where

$\mathrm{n}$ : Number of DMUs

$\mathrm{j}$ : Indexes for DMUs

$\mathrm{m}$ : Number of inputs

$\mathrm{i}=1,2, \ldots, \mathrm{m}$ : Index for inputs

$\mathrm{s}$ : Number of outputs

$\mathrm{r}=1,2, \ldots, \mathrm{s}$ : Index for outputs

$\mathrm{x}_{\mathrm{ij}}$ : The ith input of $\mathrm{DMU}_{\mathrm{j}}$

$y_{\mathrm{rj}}$ : The rth output of $\mathrm{DMU}_{\mathrm{j}}$

$\lambda_{\mathrm{j}}$ : The decision variables that represent the weights used to form a weighted average frontier composite

$\boldsymbol{\theta}$ : The efficiency for the DMUs

$\varepsilon$ : The non-Archimedean defined to be smaller than any positive real number

$\mathrm{s}_{\mathrm{i}}^{-}$: The value of slack for the ith input

$\mathrm{s}_{\mathrm{i}}^{+}$: The value of slack for the rth output

\subsection{The Input-Oriented BCC Model}

The following BCC model is an input-oriented model, such that the inputs are minimised and the outputs remain static (Banker et al., 1984):

$$
\min \theta_{0}-\varepsilon\left(\sum_{i=1}^{m} s_{i}^{-}+\sum_{r=1}^{s} s_{r}^{+}\right)
$$

Subject to

$$
\theta_{0} x_{i 0}=\sum_{j=1}^{n} x_{i j} \lambda_{j+} s_{j}^{-} i=1,2, \ldots, m
$$




$$
\begin{gathered}
y_{r 0}=\sum_{j=1}^{n} y_{r j} \lambda_{j}-s_{r}^{+} r=1,2, \ldots, s ; \\
1=\sum_{j=1}^{n} \lambda_{j} \\
0 \leq \lambda_{j}, s_{j}^{-}, s_{r}^{+} \forall i, r, j .
\end{gathered}
$$

The BCC model differs from the CCR model in the adjunction of the condition $\sum_{j=1}^{n} \lambda_{j}=1$.

\section{Discussions and Recommendations}

Table 1 presents the descriptive statistics of input and output variables used in the DEA for each year. Expect for one input - nurses for the year 2011. The table also shows that the skewness and kurtosis values are positive and this signifies that data is peaked. Moreover, in order to know the correlation level between the inputs and outputs, the researcher calculated correlation analysis. Table 2 shows that all the output variables have good correlation with all the input variables throughout the study periods.

The scores for the average pure technical (PTE), the average overall technical (OTE) and the scale (SE) efficiencies over the 5-year period are presented in Table 3. It appears from the table that PTE scores are greater than those of OTE scores in all years, reflecting the fact that the VRS model tends to classify more hospitals as efficient. Out of the hospitals within 20 regions, eight (40 percent) indicate pure technical efficiency:- Riyadh, Qaseem, Al-Ahsa, Medinah, Qaseem, Eastern, Al-Ahsa, Hafr Al-baten, Asser, Bishah, Al-Bahah, Al-Qurayyat and Qunfudh. Hospitals in these regions are on the efficient frontier and thus form the "reference set", i.e., these hospitals can be held up as an example of how to perform at an optimum level so that the 12 inefficient regions can take note and follow suit. The average PTE score among the inefficient hospitals in regions was 0.880 percent, which means that the technically inefficient hospitals could reduce their use of resources by 16 percent to maintain their current output levels. Al-Jouf hospitals perform the worst, with an average efficiency score of 0.718 which is the smallest among all the DUMs.

In the case of the CCR model, hospitals in 3 regions (20 percent) are overall technically efficient (OTE=1) and therefore lie on the efficiency frontier (the hospitals in Qaseem, Bishah and Al-Qurayyat regions); the remaining hospitals in 17 (80 percent) regions are technically lacking in efficiency. The average total efficiency score is 0.899. So, the assumption can be made that efficiency scores decrease under CRS. Among the inefficient, hospitals in 8 regions have efficiency scores which are above average. This reveals that hospitals must reduce their current input endowments by 10.1 percent. Hospitals in the Jeddah region are the least efficient hospitals with a technical efficiency score of 0.742 . This score indicates that hospitals in Jeddah could reduce their current input endowments by 25.8 percent.

The scale efficiency was also considered in the analysis and scale was calculated as the ratio between efficiency scores in the CRS and VRS models. If the value of the SE score is one, then the hospital is apparently operating at optimal scale size. Anything less than one would indicate that the hospital is either too big or too small in relative terms to its optimal scale size. Based on Table 3, we note that over the study period, only hospitals in 3 out of a possible 20 regions are scale efficient, while the remaining hospitals in 17 regions are scale inefficient. The average scale efficiency is 0.968 which indicates that on average, a hospital may have to increase its scale by 3.19 per cent beyond its best practice average targets under VRS, if it were to operate at CRS. The scores of scale-inefficient hospitals are between 0.866 and 0.998 . The average score of 17 scale-inefficient hospitals is 0.962, which would infer that on average, these specific hospitals would be able to reduce their resources by 3.75 percent, whilst simultaneously maintaining the same number of outputs.

RTS analysis indicates that the hospitals in Al-Jouf were consistently operating on IRS, hospitals in Qaseem and hospitals in Al-Qurayyat have been consistently operating on CRS and hospitals in Makkah and Medinah were consistently operating on DRS. Based on the aforementioned table, the results show that during the 5-year period, most of the hospitals across the regions were operating under DRS. On average, there were 40 counts of DRS performance (40 percent), 37 counts of CRS ( 37 percent) and 23 counts of IRS (23 percent).

DEA-calculated slacks specify the amount by which an input or output must be improved for inefficient hospitals, so that they improve their performance to become cost effective. Table 4 and Table 5 present the possible reduction in inputs and increases in outputs for hospitals in each region respectively. For example, in the case of our inefficient hospitals in Makkah, we observe that the 3 inputs are slacks, beds, doctors and nurses. 
Therefore for hospitals in Makkah to improve their level of efficiency, they must reduce beds by 18 percent, doctors by 25 percent and nurses by 20 percent, whilst simultaneously maintaining outputs (see Table 7). This represents the horizontal movement of the DMU towards the efficiency frontier. Alternatively, hospitals in Makkah do have slacks in their outputs, namely the number of inpatients and surgeries. This means, therefore, that these hospitals can move towards the efficiency frontier vertically by increasing the output of inpatients and surgeries by 1557 and 260 respectively.

The calculation results of the target values for all inputs and outputs of inefficient hospitals taken together with the percentage reduction in inputs and augmentation in outputs are presented in Table 6 and Table 7. It evidences that on average, hospitals have great potential to reduce inputs and augment outputs in accordance with the more successfully-performing hospitals. On average 5.69, 15.06 and 2.78 percent of outpatients, inpatients and surgeries respectively should be augmented along with a 14.96 percent reduction in beds, 15.43 percent cutback in doctors and 20.50 in nurses, if all inefficient hospitals operate at the efficient level. In addition to that, hospitals in 11 regions were not able to meet all their input targets; namely Makkah, Jeddah, Taif, Medinah, Eastern, Hafr Al-baten, Tabouk, Hail, Northern, Jazan, Najran and Al-Jouf. This result demonstrates the presence of slacks for the aforementioned hospitals since there was a surplus in the utilisation of their resources and an excess in spending for their operations. On the other hand, Table 6 also shows that hospitals in 8 regions consistently reached their expected targets for all inputs.

The hospitals producing on the efficient frontier are identified as "best practice" and can be regarded as role models which a DUM can emulate to achieve maximum efficiency. Table 8 summarises the peers for all the inefficient hospitals in the regions. Out of the hospitals in 20 regions, the Bishah region has emerged as the gold standard region to be mirrored by all the inefficient hospitals. This was based on the frequency with which it was used as a benchmark by the other hospitals.

Once the peer group and areas in need of improvement have been identified, hospital management can then determine what changes need to be implemented in order to foster a more coherent businesslike environment and to utilise resources more effectively.

Before concluding, sensitivity analysis was also used to investigate the stability and vigour of the efficiency scores of the BCC model. For sensitivity analysis efficient region removed one by one peer count wise. Table 9 illustrates the results of sensitivity analysis for the years 2010, 2011, 2013, 2014 and 2015. A close look at the table reveals that there are significant differences between the initial and the new efficiency scores, after removing the efficient regions with peer count. For example, if we remove R6 (peer count 6), from the reference set of the efficiency scores of regions in 2010, we note that hospitals in 10 regions are efficient with a PTE of 0.925. If we remove R11 (peer count 10) from the reference set of the efficiency scores of regions in 2015, we observe that hospitals in 10 regions are efficient with a PTE of 0.939. R12 is the efficient one after removing region R11. This indicates that inefficiency of R12 is due to R11, thus the hospitals in region R12 have a structure similar to that of hospitals in region R11. All the efficient BCC hospitals with their respective mean efficiencies are given in the table.

Table 1. Descriptive Statistics of Inputs and Outputs

\begin{tabular}{lllllll}
\hline & Mean & Std. Deviation & Minimum & Maximum & Skewness & Kurtosis \\
\hline 2010 & & & & & & \\
Beds (BED) & 1719 & 1499 & 150 & 7171 & 2.67 & 9.37 \\
Doctors (DOC) & 1562 & 1319 & 294 & 6104 & 2.29 & 6.97 \\
Nurses (NUR) & 3893 & 3419 & 691 & 15429 & 2.27 & 6.41 \\
Outpatients (OP) & 571351 & 458317 & 53645 & 2095110 & 2.00 & 5.71 \\
Inpatients (IP) & 85041 & 58688 & 14223 & 290345 & 2.28 & 7.66 \\
Surgeries (SUR) & 22509 & 20121 & 2818 & 97372 & 2.86 & 10.52 \\
2011 & & & & & & \\
Beds (BED) & 1723 & 1520 & 200 & 7322 & 2.77 & 9.97 \\
Doctors (DOC) & 1687 & 1381 & 335 & 6368 & 2.19 & 6.37 \\
Nurses (NUR) & 3892 & 3390 & 688 & 16016 & 2.57 & 8.54 \\
Outpatients (OP) & 572988 & 455959 & 67379 & 2018553 & 1.74 & 4.29 \\
Inpatients (IP) & 85009 & 57036 & 14959 & 282355 & 2.18 & 7.22 \\
Surgeries (SUR) & 22055 & 17220 & 3330 & 80581 & 2.14 & 6.49 \\
2013 & & & & & & \\
Beds (BED) & 1948 & 1663 & 200 & 7937 & 2.58 & 8.83 \\
Doctors (DOC) & 1878 & 1541 & 334 & 6985 & 2.04 & 5.57 \\
Nurses (NUR) & 4217 & 3586 & 716 & 16858 & 2.46 & 7.92 \\
\hline
\end{tabular}




\begin{tabular}{lllllll}
\hline Outpatients (OP) & 567647 & 446137 & 79549 & 1947049 & 1.62 & 3.65 \\
Inpatients (IP) & 85056 & 61528 & 14685 & 299500 & 2.26 & 7.47 \\
Surgeries (SUR) & 23118 & 21359 & 2749 & 104517 & 3.11 & 11.86 \\
2014 & & & & & & \\
Beds (BED) & 2015 & 1655 & 200 & 7937 & 2.52 & 8.58 \\
Doctors (DOC) & 1906 & 1567 & 332 & 7099 & 2.05 & 5.59 \\
Nurses (NUR) & 4568 & 3730 & 870 & 17735 & 2.44 & 7.96 \\
Outpatients (OP) & 603752 & 533575 & 75626 & 2417730 & 2.19 & 6.48 \\
Inpatients (IP) & 84968 & 56434 & 14692 & 272635 & 1.90 & 5.76 \\
Surgeries (SUR) & 24266 & 26689 & 2841 & 129126 & 3.44 & 13.77 \\
2015 & & & & & & \\
Beds (BED) & 2065 & 1643 & 350 & 7937 & 2.52 & 8.51 \\
Doctors (DOC) & 2043 & 1703 & 297 & 7652 & 2.01 & 5.38 \\
Nurses (NUR) & 4738 & 3612 & 974 & 17226 & 2.26 & 7.13 \\
Outpatients (OP) & 823748 & 706989 & 108294 & 3195512 & 2.09 & 6.00 \\
Inpatients (IP) & 85295 & 59051 & 14688 & 286068 & 2.07 & 6.52 \\
Surgeries (SUR) & 25212 & 27758 & 2950 & 135195 & 3.54 & 14.35 \\
\hline
\end{tabular}

Table 2. Co-relation Between Inputs and Outputs

\begin{tabular}{|c|c|c|c|c|c|c|}
\hline \multicolumn{7}{|l|}{2010} \\
\hline & Beds (BED) & Doctors (DOC) & Nurses (NUR) & Outpatients (OP) & Inpatients (IP) & Surgeries (SUR) \\
\hline Beds (BED) & 1.00 & $.991^{* *}$ & $.974^{* * *}$ & $.967^{* *}$ & $.963^{* *}$ & $.969^{* * *}$ \\
\hline Doctors (DOC) & $.991^{* *}$ & 1.00 & $.990^{* *}$ & $.976^{* *}$ & $.963^{* *}$ & $.956^{* *}$ \\
\hline Nurses (NUR) & $.974^{* *}$ & $.990^{* *}$ & 1.00 & $.962^{* *}$ & $.945^{* *}$ & $.935^{* * *}$ \\
\hline Outpatients (OP) & $.967^{* *}$ & $.976^{* *}$ & $.962^{* * *}$ & 1.00 & $.972^{* *}$ & $.944^{* * *}$ \\
\hline Inpatients (IP) & $.963^{* *}$ & $.963^{* *}$ & $.945^{* *}$ & $.972^{* *}$ & 1.00 & $.957^{* *}$ \\
\hline Surgeries (SUR) & $.969^{* * *}$ & $.956^{* *}$ & $.935^{* *}$ & $.944^{* *}$ & $.957^{* *}$ & 1.00 \\
\hline \multicolumn{7}{|l|}{2011} \\
\hline & Beds (BED) & Doctors (DOC) & Nurses (NUR) & Outpatients (OP) & Inpatients (IP) & Surgeries (SUR) \\
\hline Beds (BED) & 1.00 & $.985^{* *}$ & $.995^{* *}$ & $.963^{* *}$ & $.966^{* *}$ & $.967^{* * *}$ \\
\hline Doctors (DOC) & $.985^{* *}$ & 1.00 & $.994^{* *}$ & $.977^{* *}$ & $.950^{* *}$ & $.963^{* * *}$ \\
\hline Nurses (NUR) & $.995^{* *}$ & $.994^{* *}$ & 1.00 & $.971^{* *}$ & $.960^{* *}$ & $.966^{* *}$ \\
\hline Outpatients (OP) & $.963^{* *}$ & $.977^{* *}$ & $.971^{* *}$ & 1.00 & $.953^{* *}$ & $.938^{* * *}$ \\
\hline Inpatients (IP) & $.966^{* *}$ & $.950^{* *}$ & $.960^{* *}$ & $.953^{* *}$ & 1.00 & $.961^{* *}$ \\
\hline Surgeries (SUR) & $.967^{* * *}$ & $.963^{* * *}$ & $.966^{* *}$ & $.938^{* *}$ & $.961^{* *}$ & 1.00 \\
\hline \multicolumn{7}{|l|}{2013} \\
\hline & Beds (BED) & Doctors (DOC) & Nurses (NUR) & Outpatients (OP) & Inpatients (IP) & Surgeries (SUR) \\
\hline Beds (BED) & 1.00 & $.982^{* *}$ & $.989^{* *}$ & $.964^{* *}$ & $.958^{* *}$ & $.974^{* * *}$ \\
\hline Doctors (DOC) & $.982^{* *}$ & 1.00 & $.989^{* *}$ & $.970^{* *}$ & $.938^{* *}$ & $.943^{* * *}$ \\
\hline Nurses (NUR) & $.989^{* *}$ & $.989^{* *}$ & 1.00 & $.973^{* *}$ & $.954^{* *}$ & $.962^{* *}$ \\
\hline Outpatients (OP) & $.964^{* *}$ & $.970^{* *}$ & $.973^{* *}$ & 1.00 & $.945^{* *}$ & $.912^{* *}$ \\
\hline Inpatients (IP) & $.958^{* *}$ & $.938^{* *}$ & $.954^{* *}$ & $.945^{* *}$ & 1.00 & $.967^{* *}$ \\
\hline Surgeries (SUR) & $.974^{* *}$ & $.943^{* *}$ & $.962^{* *}$ & $.912^{* *}$ & $.967^{* *}$ & 1.00 \\
\hline \multicolumn{7}{|l|}{2014} \\
\hline & Beds (BED) & Doctors (DOC) & Nurses (NUR) & Outpatients (OP) & Inpatients (IP) & Surgeries (SUR) \\
\hline Beds (BED) & 1.00 & $.982 * *$ & $.993^{* *}$ & $.983 * *$ & $.954 * *$ & $.964 * *$ \\
\hline Doctors (DOC) & $.982 * *$ & 1.00 & $.990^{* *}$ & $.980 * *$ & $.939 * *$ & $.929 * *$ \\
\hline Nurses (NUR) & $.993 * *$ & $.990 * *$ & 1.00 & $.983 * *$ & $.953 * *$ & $.959^{* *}$ \\
\hline Outpatients (OP) & $.983 * *$ & $.980 * *$ & $.983^{* *}$ & 1.00 & $.958^{* *}$ & $.930^{* *}$ \\
\hline Inpatients (IP) & $.954 * *$ & $.939 * *$ & $.953^{* *}$ & $.958^{* *}$ & 1.00 & $.940^{* *}$ \\
\hline Surgeries (SUR) & $.964 * *$ & $.929 * *$ & $.959^{* *}$ & $.930 * *$ & $.940 * *$ & 1.00 \\
\hline \multicolumn{7}{|l|}{2015} \\
\hline & Beds (BED) & Doctors (DOC) & Nurses (NUR) & Outpatients (OP) & Inpatients (IP) & Surgeries (SUR) \\
\hline Beds (BED) & 1.00 & $.985^{* *}$ & $.993^{* *}$ & $.979^{* *}$ & $.956^{* *}$ & $.961^{* *}$ \\
\hline Doctors (DOC) & $.985^{* *}$ & 1.00 & $.991^{* *}$ & $.973^{* *}$ & $.935^{* *}$ & $.923^{* *}$ \\
\hline Nurses (NUR) & $.993^{* *}$ & $.991^{* *}$ & 1.00 & $.979^{* *}$ & $.949^{* *}$ & $.946^{* *}$ \\
\hline Outpatients (OP) & $.979^{* *}$ & $.973^{* *}$ & $.979^{* *}$ & 1.00 & $.958^{* *}$ & $.924^{* *}$ \\
\hline Inpatients (IP) & $.956^{* *}$ & $.935^{* *}$ & $.949^{* *}$ & $.958^{* *}$ & 1.00 & $.945^{* *}$ \\
\hline Surgeries (SUR) & $.961^{* *}$ & $.923^{* *}$ & $.946^{* *}$ & $.924^{* *}$ & $.945^{* *}$ & 1.00 \\
\hline
\end{tabular}


Table 3. Overall, pur, scale efficiencies and return to scale

\begin{tabular}{|c|c|c|c|c|c|c|c|c|c|c|c|c|c|c|c|c|c|c|c|c|c|c|c|}
\hline \multirow[b]{2}{*}{ Regions } & \multicolumn{4}{|c|}{ Efficiency: 2010} & \multicolumn{4}{|c|}{ EFficiency: 2011} & \multicolumn{4}{|c|}{ EFf̆iciency: 2013} & \multicolumn{4}{|c|}{ Efficiency: 2014} & \multicolumn{4}{|c|}{ Efriciency: 2015} & \multicolumn{3}{|c|}{ Average } \\
\hline & OTE & PTE & $\mathrm{SE}$ & RTS & оте & PTE & $\mathrm{SE}$ & RTS & оте & PTE & SE & RTS & оте & PTE & $\mathrm{SE}$ & RTS & отЕ & PTE & $\mathrm{SE}$ & RTS & ОTE & PTE & $\mathrm{SE}$ \\
\hline Rijyath & 0.731 & 1.000 & 0.731 & DRS & 0.780 & 1.000 & 0.780 & DRS & 0.820 & 1.000 & 0.820 & DRS & 1.000 & 1.000 & 1.000 & CRS & 1.000 & 1.000 & 1.000 & CRS & 0.866 & 1.000 & 0.866 \\
\hline Makkah & 0.722 & 0.754 & 0.958 & DRS & 0.869 & 0.877 & 0.991 & DRS & 0.766 & 0.778 & 0.984 & DRS & 0.895 & 0.908 & 0.986 & DRS & 0.837 & 0.839 & 0.997 & DRS & 0.818 & 0.831 & 0.983 \\
\hline Jeddah & 0.669 & 0.754 & 0.887 & DRS & 0.794 & 0.809 & 0.982 & DRS & 0.748 & 0.833 & 0.998 & DRS & 0.771 & 0.772 & 1.000 & IRS & 0.727 & 0.730 & 0.997 & DRS & 0.742 & 0.779 & 0.953 \\
\hline Taif & 0.759 & 0.763 & 0.995 & IRS & 0.852 & 0.854 & 0.998 & IRS & 0.893 & 0.909 & 0.982 & DRS & 0.826 & 0.841 & 0.981 & DRS & 0.865 & 0.866 & 0.998 & DRS & 0.839 & 0.847 & 0.991 \\
\hline Medinah & 0.795 & 0.820 & 0.970 & DRS & 0.778 & 0.834 & 0.934 & DRS & 0.930 & 1.000 & 0.930 & DRS & 0.947 & 0.959 & 0.987 & DRS & 0.945 & 0.951 & 0.993 & DRS & 0.879 & 0.913 & 0.963 \\
\hline Qascem & 1.000 & 1.000 & 1.000 & CRS & 1.000 & 1.000 & 1.000 & CRS & 1.000 & 1.000 & 1.000 & CRS & 1.000 & 1.000 & 1.000 & CRS & 1.000 & 1.000 & 1.000 & CRS & 1.000 & 1.000 & 1.000 \\
\hline Eastem & 0.780 & 0.805 & 0.969 & DRS & 0.911 & 1.000 & 0.911 & DRS & 0.935 & 1.000 & 0.935 & DRS & 1.000 & 1.000 & 1.000 & CRS & 1.000 & 1.000 & 1.000 & CRS & 0.925 & 0.961 & 0.963 \\
\hline Al-Ahsa & 0.907 & 1.000 & 0.907 & DRS & 1.000 & 1.000 & 1.000 & CRS & 1.000 & 1.000 & 1.000 & CRS & 0.964 & 1.000 & 0.964 & DRS & 0.936 & 1.000 & 0.936 & DRS & 0.961 & 1.000 & 0.961 \\
\hline Haff A-baten & 0.816 & 0.934 & 0.874 & IRS & 0.892 & 0.995 & 0.897 & CRS & 0.815 & 0.858 & 0.950 & IRS & 0.697 & 0.732 & 0.953 & IRS & 0.628 & 0.671 & 0.936 & IRS & 0.770 & 0.838 & 0.922 \\
\hline Asser & 0.953 & 1.000 & 0.953 & DRS & 1.000 & 1.000 & 1.000 & CRS & 0.924 & 1.000 & 0.924 & DRS & 1.000 & 1.000 & 1.000 & CRS & 1.000 & 1.000 & 1.000 & CRS & 0.975 & 1.000 & 0.975 \\
\hline Bishah & 1.000 & 1.000 & 1.000 & CRS & 0.998 & 1.000 & 0.998 & IRS & 1.000 & 1.000 & 1.000 & CRS & 1.000 & 1.000 & 1.000 & CRS & 1.000 & 1.000 & 1.000 & CRS & 1.000 & 1.000 & 1.000 \\
\hline Tabouk & 1.000 & 1.000 & 1.000 & CRS & 0.891 & 0.999 & 0.980 & IRS & 0.877 & 0.884 & 0.992 & IRS & 0.973 & 0.974 & 0.999 & DRS & 0.969 & 0.994 & 0.975 & IRS & 0.942 & 0.952 & 0.989 \\
\hline Hail & 0.842 & 0.934 & 0.902 & DRS & 0.873 & 0.947 & 0.922 & DRS & 0.930 & 0.933 & 0.996 & IRS & 0.965 & 1.000 & 0.965 & DRS & 0.970 & 1.000 & 0.970 & DRS & 0.916 & 0.963 & 0.951 \\
\hline Northem & 1.000 & 1.000 & 1.000 & CRS & 1.000 & 1.000 & 1.000 & CRS & 0.813 & 0.819 & 0.993 & IRS & 0.912 & 0.939 & 0.971 & DRS & 0.094 & 0.740 & 0.938 & DRS & 0.884 & 0.900 & 0.980 \\
\hline Jazan & 0.999 & 1.000 & 0.999 & DRS & 1.000 & 1.000 & 1.000 & CRS & 1.000 & 1.000 & 1.000 & CRS & 1.000 & 1.000 & 1.000 & CRS & 0.978 & 0.987 & 0.990 & DRS & 0.995 & 0.997 & 0.998 \\
\hline Najian & 0.770 & 0.777 & 0.991 & DRS & 0.823 & 0.829 & 0.993 & IRS & 0.910 & 0.913 & 0.997 & IRS & 0.859 & 0.890 & 0.965 & DRS & 0.862 & 0.888 & 0.970 & DRS & 0.845 & 0.859 & 0.983 \\
\hline A-Bataha & 0.959 & 1.000 & 0.959 & IRS & 1.000 & 1.000 & 1.000 & CRS & 1.000 & 1.000 & 1.000 & CRS & 1.000 & 1.000 & 1.000 & CRS & 1.000 & 1.000 & 1.000 & CRS & 0.992 & 1.000 & 0.992 \\
\hline Al-Jouf & 0.690 & 0.757 & 0.912 & IRS & 0.681 & 0.749 & 0.909 & IRS & 0.798 & 0.814 & 0.979 & IRS & 0.647 & 0.675 & 0.959 & IRS & 0.590 & 0.593 & 0.995 & IRS & 0.681 & 0.718 & 0.951 \\
\hline Al-Qurayyat & 1.000 & 1.000 & 1.000 & CRS & 1.000 & 1.000 & 1.000 & CRS & 1.000 & 1.000 & 1.000 & CRS & 1.000 & 1.000 & 1.000 & CRS & 1.000 & 1.000 & 1.000 & CRS & 1.000 & 1.000 & 1.000 \\
\hline Qunfidh & 1.000 & 1.000 & 1.000 & CRS & 0.989 & 1.000 & 0.989 & IRS & 1.000 & 1.000 & 1.000 & CRS & 1.000 & 1.000 & 1.000 & CRS & 0.712 & 1.000 & 0.712 & IRS & 0.940 & 1.000 & 0.940 \\
\hline Mean & & & & & & & & & & & & & & & & & & & & & 0.899 & 0.928 & 0.968 \\
\hline
\end{tabular}

Table 4. Input Slacks of BCC model

\begin{tabular}{|c|c|c|c|c|c|c|c|c|c|c|c|c|c|c|c|c|c|c|}
\hline \multirow[b]{2}{*}{ Regions } & \multicolumn{3}{|c|}{ Slacks: 2010} & \multicolumn{3}{|c|}{ Slacks: 2011} & \multicolumn{3}{|c|}{ Slacks: 2013} & \multicolumn{3}{|c|}{ Slacks: 2014} & \multicolumn{3}{|c|}{ Slacks 2015} & \multicolumn{3}{|c|}{ Average } \\
\hline & BED & DOC & NUR & BED & $\mathrm{DOC}$ & NUR & BED & DOC & NUR & BED & DOC & NUR & (BED) & DOC & NUR & (BED) & DOC & NUR \\
\hline Riyadh & 0 & 0 & 0 & 0 & 0 & 0 & 0 & 0 & 0 & 0 & 0 & 0 & 0 & 0 & 0 & 0 & 0 & 0 \\
\hline Makkah & 4 & 19 & 0 & 84 & 0 & 0 & 0 & 226 & 0 & 0 & 462 & 633 & 0 & 430 & 241 & 18 & 227 & 175 \\
\hline Jeddah & 295 & 208 & 0 & 60 & 306 & 0 & 134 & 555 & 0 & 0 & 411 & 0 & 0 & 440 & 0 & 98 & 384 & 0 \\
\hline Taif & 177 & 0 & 472 & 192 & 0 & 345 & 321 & 0 & 238 & 139 & 0 & 275 & 0 & 0 & 437 & 166 & 0 & 353 \\
\hline Medinah & 0 & 95 & 125 & 0 & 0 & 67 & 0 & 0 & 0 & 0 & 414 & 1066 & 0 & 293 & 639 & 0 & 161 & 379 \\
\hline Qaseem & 0 & 0 & 0 & 0 & 0 & 0 & 0 & 0 & 0 & 0 & 0 & 0 & 0 & 0 & 0 & 0 & 0 & 0 \\
\hline Eastern & 0 & 268 & 2376 & 0 & 0 & 0 & 0 & 0 & 0 & 0 & 0 & 0 & 0 & 0 & 0 & 0 & 54 & 475 \\
\hline Al-Ahsa & 0 & 0 & 0 & 0 & 0 & 0 & 0 & 0 & 0 & 0 & 0 & 0 & 0 & 0 & 0 & 0 & 0 & 0 \\
\hline Hafr Al-baten & 0 & 0 & 93 & 0 & 0 & 103 & 171 & 0 & 269 & 42 & 0 & 212 & 0 & 0 & 518 & 43 & 0 & 239 \\
\hline Asser & 0 & 0 & 0 & 0 & 0 & 0 & 0 & 0 & 0 & 0 & 0 & 0 & 0 & 0 & 0 & 0 & 0 & 0 \\
\hline Bishah & 0 & 0 & 0 & 0 & 0 & 0 & 0 & 0 & 0 & 0 & 0 & 0 & 0 & 0 & 0 & 0 & 0 & 0 \\
\hline Tabouk & 0 & 0 & 0 & 0 & 0 & 0 & 0 & 0 & 281 & 0 & 30 & 531 & 0 & 284 & 1231 & 0 & 63 & 409 \\
\hline Hail & 0 & 61 & 305 & 0 & 12 & 212 & 0 & 0 & 442 & 0 & 0 & 0 & 0 & 0 & 0 & 0 & 15 & 192 \\
\hline Northern & 0 & 0 & 0 & 0 & 0 & 0 & 0 & 0 & 244 & 0 & 79 & 341 & 33 & 0 & 190 & 7 & 16 & 155 \\
\hline Jazan & 0 & 0 & 0 & 0 & 0 & 0 & 0 & 0 & 0 & 0 & 0 & 0 & 0 & 54 & 206 & 0 & 11 & 41 \\
\hline Najran & 0 & 0 & 116 & 23 & 0 & 0 & 0 & 0 & 41 & 0 & 129 & 236 & 0 & 178 & 756 & 5 & 61 & 230 \\
\hline Al-Bahah & 0 & 0 & 0 & 0 & 0 & 0 & 0 & 0 & 0 & 0 & 0 & 0 & 0 & 0 & 0 & 0 & 0 & 0 \\
\hline Al-Jouf & 61 & 0 & 129 & 0 & 0 & 95 & 0 & 0 & 498 & 124 & 0 & 324 & 0 & 0 & 599 & 37 & 0 & 329 \\
\hline Al-Qurayyat & 0 & 0 & 0 & 0 & 0 & 0 & 0 & 0 & 0 & 0 & 0 & 0 & 0 & 0 & 0 & 0 & 0 & 0 \\
\hline Qunfudh & 0 & 0 & 0 & 0 & 0 & 0 & 0 & 0 & 0 & 0 & 0 & 0 & 0 & 0 & 0 & 0 & 0 & 0 \\
\hline
\end{tabular}

Table 5. Outpu Slacks of BCC Model

\begin{tabular}{|c|c|c|c|c|c|c|c|c|c|c|c|c|c|c|c|c|c|c|}
\hline \multirow[b]{2}{*}{ Regions } & \multicolumn{3}{|c|}{ Slacks: 2010} & \multicolumn{3}{|c|}{ Slacks: 2011} & \multicolumn{3}{|c|}{ Slacks: 2013} & \multicolumn{3}{|c|}{ Slacks: 2014} & \multicolumn{3}{|c|}{ Slacks 2015} & \multicolumn{3}{|c|}{ Average } \\
\hline & $\mathrm{OP}$ & IP & SUR & $\mathrm{OP}$ & IP & SUR & $\mathrm{OP}$ & IP & SUR & $\mathrm{OP}$ & IP & SUR & $\mathrm{OP}$ & IP & SUR & $\mathrm{OP}$ & IP & SUR \\
\hline Riyadh & 0 & 0 & 0 & 0 & 0 & 0 & 0 & 0 & 0 & 0 & 0 & 0 & 0 & 0 & 0 & 0 & 0 & 0 \\
\hline Makkah & 0 & 0 & 0 & 0 & 0 & 0 & 0 & 3861 & 0 & 0 & 3926 & 0 & 0 & 0 & 1298 & 0 & 1557 & 260 \\
\hline Jeddah & 0 & 0 & 0 & 0 & 19483 & 0 & 0 & 32349 & 0 & 0 & 21543 & 0 & 0 & 23137 & 0 & 0 & 19302 & 0 \\
\hline Taif & 0 & 0 & 0 & 0 & 0 & 0 & 0 & 5844 & 0 & 0 & 0 & 0 & 0 & 1806 & 0 & 0 & 1530 & 0 \\
\hline Medinah & 0 & 0 & 1789 & 42117 & 0 & 0 & 0 & 0 & 0 & 0 & 0 & 0 & 0 & 2349 & 0 & 8423 & 470 & 358 \\
\hline Qaseem & 0 & 0 & 0 & 0 & 0 & 0 & 0 & 0 & 0 & 0 & 0 & 0 & 0 & 0 & 0 & 0 & 0 & 0 \\
\hline Eastern & 0 & 4721 & 0 & 0 & 0 & 0 & 0 & 0 & 0 & 0 & 0 & 0 & 0 & 0 & 0 & 0 & 944 & 0 \\
\hline Al-Ahsa & 0 & 0 & 0 & 0 & 0 & 0 & 0 & 0 & 0 & 0 & 0 & 0 & 0 & 0 & 0 & 0 & 0 & 0 \\
\hline Hafr Al-baten & 0 & 7446 & 0 & 0 & 7553 & 0 & 7050 & 22643 & 0 & 0 & 20409 & 0 & 0 & 16279 & 0 & 1410 & 14866 & 0 \\
\hline Asser & 0 & 0 & 0 & 0 & 0 & 0 & 0 & 0 & 0 & 0 & 0 & 0 & 0 & 0 & 0 & 0 & 0 & 0 \\
\hline Bishah & 0 & 0 & 0 & 0 & 0 & 0 & 0 & 0 & 0 & 0 & 0 & 0 & 0 & 0 & 0 & 0 & 0 & 0 \\
\hline Tabouk & 0 & 0 & 0 & 0 & 2301 & 0 & 0 & 2827 & 0 & 0 & 0 & 0 & 0 & 3295 & 0 & 0 & 1685 & 0 \\
\hline Hail & 92931 & 0 & 813 & 66167 & 0 & 0 & 0 & 0 & 0 & 0 & 0 & 0 & 0 & 0 & 0 & 31820 & 0 & 163 \\
\hline Northern & 0 & 0 & 0 & 0 & 0 & 0 & 56757 & 0 & 0 & 1364 & 0 & 0 & 51592 & 0 & 0 & 21942 & 0 & 0 \\
\hline
\end{tabular}




\begin{tabular}{lllllllllllllllllll}
\hline Jazan & 0 & 0 & 0 & 0 & 0 & 0 & 0 & 0 & 0 & 0 & 0 & 0 & 0 & 0 & 6743 & 0 & 0 & 1349 \\
Najran & 12264 & 0 & 0 & 0 & 0 & 0 & 0 & 4189 & 0 & 0 & 0 & 0 & 0 & 0 & 0 & 2453 & 838 & 0 \\
Al-Bahah & 0 & 0 & 0 & 0 & 0 & 0 & 0 & 0 & 0 & 0 & 0 & 0 & 0 & 0 & 0 & 0 & 0 & 0 \\
Al-Jouf & 0 & 15895 & 174 & 0 & 18446 & 0 & 0 & 5572 & 0 & 0 & 12024 & 0 & 0 & 8499 & 1814 & 0 & 12087 & 398 \\
Al-Qurayyat & 0 & 0 & 0 & 0 & 0 & 0 & 0 & 0 & 0 & 0 & 0 & 0 & 0 & 0 & 0 & 0 & 0 & 0 \\
Qunfudh & 0 & 0 & 0 & 0 & 0 & 0 & 0 & 0 & 0 & 0 & 0 & 0 & 0 & 0 & 0 & 0 & 0 & 0 \\
\hline
\end{tabular}

Table 6. Efficient targets in output under BCC model

\begin{tabular}{|c|c|c|c|c|c|c|c|c|c|c|c|c|c|c|c|c|c|c|}
\hline \multirow{4}{*}{ Regions } & \multirow{2}{*}{\multicolumn{3}{|c|}{$\begin{array}{l}\text { Slacks: } 2010 \\
\text { Possible Increase } \\
\end{array}$}} & \multicolumn{3}{|c|}{ Slacks: 2011} & \multicolumn{3}{|c|}{ Slacks: 2013} & \multicolumn{3}{|c|}{ Slacks: 2014} & \multicolumn{3}{|c|}{ Slacks 2015} & \multirow{2}{*}{\multicolumn{3}{|c|}{$\begin{array}{l}\text { Average } \\
\text { Possible Increase }\end{array}$}} \\
\hline & & & & \multicolumn{2}{|c|}{ Possible I } & Increase & \multicolumn{2}{|c|}{ Possible I } & Increase & \multicolumn{2}{|c|}{ Possible I } & Increasen & \multicolumn{2}{|c|}{ Possible } & Increase & & & \\
\hline & $\mathrm{OP}$ & IP & SUR & $\mathrm{OP}$ & IP & SUR & $\mathrm{OP}$ & IP & SUR & $\mathrm{OP}$ & IP & SUR & $\mathrm{OP}$ & IP & SUR & $\mathrm{OP}$ & IP & SUR \\
\hline & $(\%)$ & $(\%)$ & $(\%)$ & $(\%)$ & $(\%)$ & $(\%)$ & $(\%)$ & $(\%)$ & $(\%)$ & $(\%)$ & $(\%)$ & $(\%)$ & $(\%)$ & $(\%)$ & $(\%)$ & $(\%)$ & $(\%)$ & $(\%)$ \\
\hline Riyadh & 0 & 0 & 0 & 0 & 0 & 0 & 0 & 22 & 0 & 0 & 0 & 0 & 0 & 0 & 0 & 0 & 4 & 0 \\
\hline Makkah & 0 & 0 & 0 & 0 & 0 & 0 & 0 & 2 & 0 & 0 & 4 & 0 & 0 & 0 & 5 & 0 & 1 & 1 \\
\hline Jeddah & 0 & 0 & 0 & 0 & 22 & 0 & 0 & 34 & 0 & 0 & 24 & 0 & 0 & 26 & 0 & 0 & 21 & 0 \\
\hline Taif & 0 & 0 & 0 & 0 & 0 & 0 & 0 & 5 & 0 & 0 & 0 & 0 & 0 & 2 & 0 & 0 & 1 & 0 \\
\hline Medinah & 0 & 0 & 6 & 5 & 0 & 0 & 0 & 28 & 0 & 0 & 0 & 0 & 0 & 2 & 0 & 1 & 6 & 1 \\
\hline Qaseem & 0 & 0 & 0 & 0 & 0 & 0 & 0 & 0 & 0 & 0 & 0 & 0 & 0 & 0 & 0 & 0 & 0 & 0 \\
\hline Eastern & 0 & 4 & 0 & 0 & 0 & 0 & 0 & 64 & 16 & 0 & 0 & 0 & 0 & 0 & 0 & 0 & 14 & 3 \\
\hline Al-Ahsa & 0 & 0 & 0 & 0 & 0 & 0 & 0 & 0 & 0 & 0 & 0 & 0 & 0 & 0 & 0 & 0 & 0 & 0 \\
\hline Hafr Al-baten & 0 & 29 & 0 & 0 & 28 & 0 & 0 & 73 & 0 & 0 & 91 & 0 & 0 & 78 & 0 & 0 & 60 & 0 \\
\hline Asser & 0 & 0 & 0 & 0 & 0 & 0 & 0 & 2 & 0 & 0 & 0 & 0 & 0 & 0 & 0 & 0 & 0 & 0 \\
\hline Bishah & 0 & 0 & 0 & 0 & 0 & 0 & 0 & 0 & 0 & 0 & 0 & 0 & 0 & 0 & 0 & 0 & 0 & 0 \\
\hline Tabouk & 0 & 0 & 0 & 0 & 4 & 0 & 0 & 12 & 0 & 0 & 0 & 0 & 0 & -6 & 0 & 0 & 2 & 0 \\
\hline Hail & 32 & 0 & 6 & 23 & 0 & 0 & 0 & 0 & 0 & 0 & 0 & 0 & 0 & 0 & 0 & 11 & 0 & 1 \\
\hline Northern & 0 & 0 & 0 & 0 & 0 & 0 & 30 & 0 & 0 & 1 & 0 & 0 & 18 & 0 & 0 & 10 & 0 & 0 \\
\hline Jazan & 0 & 0 & 0 & 0 & 0 & 0 & 0 & 0 & 0 & 0 & 0 & 0 & 0 & 0 & 33 & 0 & 0 & 7 \\
\hline Najran & 4 & 0 & 0 & 0 & 0 & 0 & 0 & 11 & 0 & 0 & 0 & 0 & 0 & 0 & 0 & 1 & 2 & 0 \\
\hline Al-Bahah & 0 & 0 & 0 & 0 & 0 & 0 & 0 & 0 & 0 & 0 & 0 & 0 & 0 & 0 & 0 & 0 & 0 & 0 \\
\hline Al-Jouf & 0 & 52 & 3 & 0 & 62 & 0 & 0 & 15 & 0 & 0 & 37 & 0 & 0 & 26 & 17 & 0 & 38 & 4 \\
\hline Al-Qurayyat & 0 & 0 & 0 & 0 & 0 & 0 & 0 & 0 & 0 & 0 & 0 & 0 & 0 & 0 & 0 & 0 & 0 & 0 \\
\hline Qunfudh & 0 & 0 & 0 & 0 & 0 & 0 & 0 & 0 & 0 & 0 & 0 & 0 & 0 & 0 & 0 & 0 & 0 & 0 \\
\hline Avergae & & & & & & & & & & & & & & & & 5.69 & 15.06 & 2.87 \\
\hline
\end{tabular}

Table 7. Efficient targets in input under BCC model

\begin{tabular}{|c|c|c|c|c|c|c|c|c|c|c|c|c|c|c|c|c|c|c|}
\hline \multirow{4}{*}{ Regions } & \multicolumn{3}{|c|}{ Slacks: 2010} & \multicolumn{3}{|c|}{ Slacks: 2011} & \multicolumn{3}{|c|}{ Slacks: 2013} & \multicolumn{3}{|c|}{ Slacks: 2014} & \multicolumn{3}{|c|}{ Slacks 2015} & \multicolumn{3}{|c|}{ Average } \\
\hline & \multicolumn{3}{|c|}{ Possible Reduction } & \multicolumn{3}{|c|}{ Possible Reduction } & \multicolumn{3}{|c|}{ Possible Reduction } & \multicolumn{3}{|c|}{ Possible Reduction } & \multicolumn{3}{|c|}{ Possible Reduction } & \multicolumn{3}{|c|}{ Possible Reduction } \\
\hline & BED & DOC & NUR & BED & $\mathrm{DOC}$ & NUR & BED & DOC & NUR & BED & DOC & NUR & BED & DOC & NUR & BED & DOC & NUR \\
\hline & $(\%)$ & $(\%)$ & $(\%)$ & $(\%)$ & $(\%)$ & $(\%)$ & $(\%)$ & $(\%)$ & $(\%)$ & $(\%)$ & $(\%)$ & $(\%)$ & $(\%)$ & $(\%)$ & $(\%)$ & $(\%)$ & $(\%)$ & $(\%)$ \\
\hline Riyadh & 0.0 & 0 & 0 & 0 & 0 & 0 & 0 & 0 & 0 & 0 & 0 & 0 & 0 & 0 & 0 & 0 & 0 & 0 \\
\hline Makkah & 24.8 & 26 & 25 & 17 & 12 & 12 & 22 & 30 & 22 & 9 & 25 & 19 & 16 & 30 & 20 & 18 & 25 & 20 \\
\hline Jeddah & 34.9 & 33 & 25 & 22 & 30 & 19 & 21 & 34 & 17 & 23 & 35 & 23 & 27 & 39 & 27 & 26 & 34 & 22 \\
\hline Taif & 32.7 & 24 & 35 & 24 & 15 & 23 & 22 & 9 & 15 & 22 & 16 & 21 & 13 & 13 & 22 & 23 & 15 & 23 \\
\hline Medinah & 18.0 & 22 & 20 & 17 & 17 & 18 & 0 & 0 & 0 & 4 & 18 & 19 & 5 & 14 & 14 & 9 & 14 & 14 \\
\hline Qaseem & 0.0 & 0 & 0 & 0 & 0 & 0 & 0 & 0 & 0 & 0 & 0 & 0 & 0 & 0 & 0 & 0 & 0 & 0 \\
\hline Eastern & 19.5 & 29 & 46 & 0 & 0 & 0 & 0 & 0 & 0 & 0 & 0 & 0 & 0 & 0 & 0 & 4 & 6 & 9 \\
\hline Al-Ahsa & 0.0 & 0 & 0 & 0 & 0 & 0 & 0 & 0 & 0 & 0 & 0 & 0 & 0 & 0 & 0 & 0 & 0 & 0 \\
\hline Hafr Al-baten & 6.6 & 7 & 14 & 0 & 0 & 8 & 31 & 14 & 30 & 31 & 27 & 37 & 33 & 33 & 53 & 20 & 16 & 28 \\
\hline Asser & 0.0 & 0 & 0 & 0 & 0 & 0 & 0 & 0 & 0 & 0 & 0 & 0 & 0 & 0 & 0 & 0 & 0 & 0 \\
\hline Bishah & 0.0 & 0 & 0 & 0 & 0 & 0 & 0 & 0 & 0 & 0 & 0 & 0 & 0 & 0 & 0 & 0 & 0 & 0 \\
\hline Tabouk & 0.0 & 0 & 0 & 9 & 9 & 9 & 12 & 12 & 21 & 3 & 5 & 19 & 1 & 22 & 35 & 5 & 9 & 17 \\
\hline Hail & 6.6 & 13 & 19 & 5 & 6 & 14 & 7 & 7 & 22 & 0 & 0 & 0 & 0 & 0 & 0 & 4 & 5 & 11 \\
\hline Northern & 0.0 & 0 & 0 & 0 & 0 & 0 & 18 & 18 & 29 & 6 & 15 & 20 & 29 & 26 & 33 & 11 & 12 & 17 \\
\hline Jazan & 0.0 & 0 & 0 & 0 & 0 & 0 & 0 & 0 & 0 & 0 & 0 & 0 & 1 & 4 & 5 & 0 & 1 & 1 \\
\hline Najran & 22.3 & 22 & 27 & 19 & 17 & 17 & 9 & 9 & 10 & 11 & 23 & 20 & 11 & 26 & 36 & 14 & 19 & 22 \\
\hline Al-Bahah & 0.0 & 0 & 0 & 0 & 0 & 0 & 0 & 0 & 0 & 0 & 0 & 0 & 0 & 0 & 0 & 0 & 0 & 0 \\
\hline Al-Jouf & 31.5 & 24 & 31 & 25 & 25 & 30 & 19 & 19 & 41 & 42 & 32 & 45 & 41 & 41 & 60 & 32 & 28 & 41 \\
\hline Al-Qurayyat & 0.0 & 0 & 0 & 0 & 0 & 0 & 0 & 0 & 0 & 0 & 0 & 0 & 0 & 0 & 0 & 0 & 0 & 0 \\
\hline Qunfudh & 0.0 & 0 & 0 & 0 & 0 & 0 & 0 & 0 & 0 & 0 & 0 & 0 & 0 & 0 & 0 & 0 & 0 & 0 \\
\hline Avergae & & & & & & & & & & & & & & & & 14.96 & 15.43 & 20.50 \\
\hline
\end{tabular}


Table 8. Peers of inefficient regions

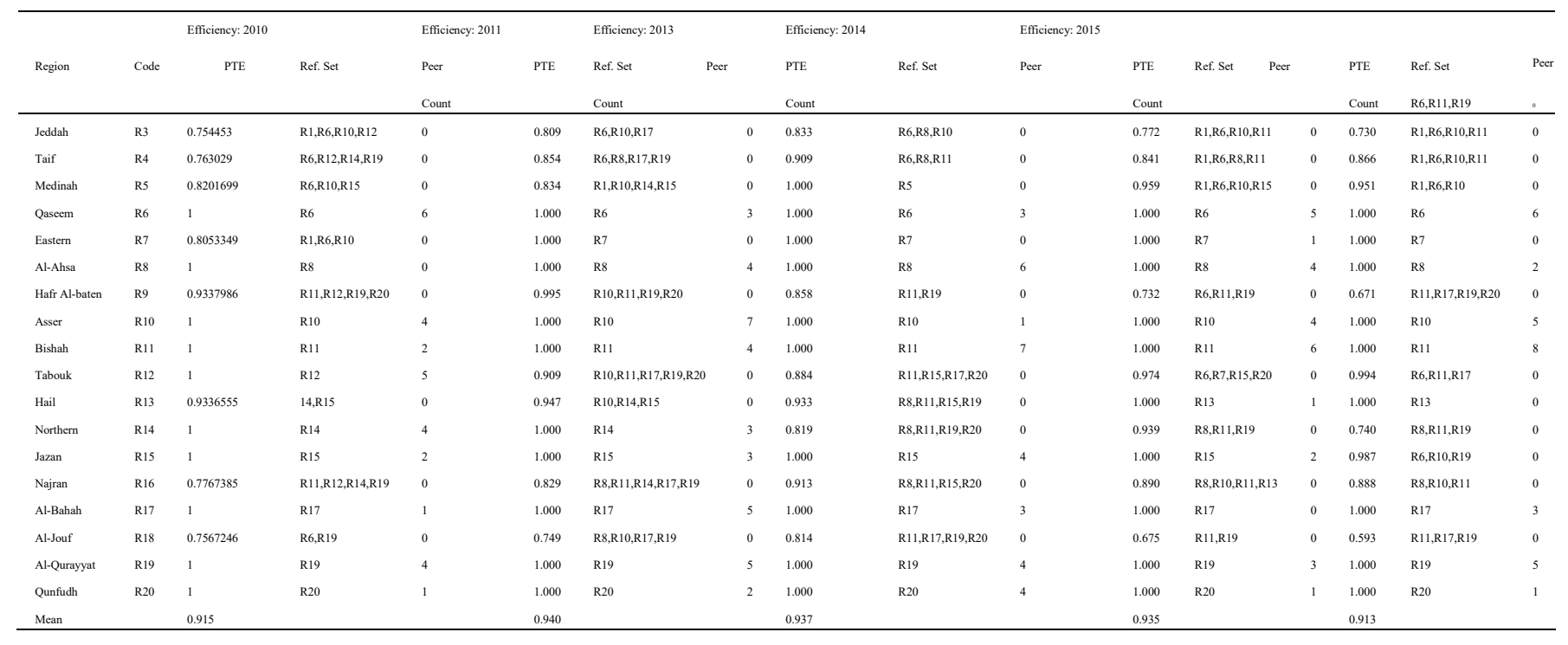

Table 9. Sensitivity analysis

\begin{tabular}{|c|c|c|c|c|c|c|c|c|c|}
\hline \multicolumn{2}{|c|}{ Efficiency Scores: 2010} & \multicolumn{8}{|c|}{ Efficiency Scores: 2011} \\
\hline $\begin{array}{c}\text { Efficient region } \\
\text { to be removed }\end{array}$ & $\begin{array}{l}\text { Peer } \\
\text { count }\end{array}$ & \multicolumn{2}{|c|}{ Mean PTE } & $\begin{array}{l}\text { New efficient } \\
\text { region }\end{array}$ & $\begin{array}{r}\text { Efficient region } \\
\text { to be removed }\end{array}$ & $\begin{array}{l}\text { Peer } \\
\text { count }\end{array}$ & \multicolumn{2}{|c|}{ Mean PTE } & $\begin{array}{l}\text { New efficient } \\
\text { region }\end{array}$ \\
\hline Qaseem & 6 & 0.915 & 0.925 & & Asser & 7 & 0.940 & 0.954 & $\begin{array}{l}\text { Medinah } \\
\text { Hafr Al-baten }\end{array}$ \\
\hline Tabouk & 5 & & 0.918 & & Al-Bahah & 5 & & 0.940 & \\
\hline Asser & 4 & & 0.921 & & Al-Qurayyat & 5 & & 0.940 & Hafr Al-baten \\
\hline Northern & 4 & & 0.919 & Hail & Al-Ahsa & 4 & & 0.939 & \\
\hline Al-Qurayyat & 4 & & 0.916 & & Bishah & 3 & & 0.938 & \\
\hline Riyadh & 2 & & 0.921 & Eastern & Qaseem & 3 & & 0.938 & \\
\hline Bishah & 2 & & 0.915 & & Northern & 3 & & 0.940 & Hail \\
\hline Jazan & 2 & & 0.911 & & Jazan & 3 & & 0.938 & \\
\hline \multirow[t]{2}{*}{ Qunfudh } & 1 & & 0.914 & Hafr Al-baten & Qunfudh & 2 & & 0.937 & Hafr Al-baten \\
\hline & & & & & Riyadh & 1 & & 0.946 & Medinah \\
\hline \multicolumn{2}{|c|}{ Efficiency Scores: 2013} & \multicolumn{8}{|c|}{ Efficiency Scores: 2014} \\
\hline \multirow{2}{*}{$\begin{array}{l}\text { Efficient region } \\
\text { to be removed }\end{array}$} & Peer & \multicolumn{2}{|c|}{ Mean PTE } & New efficient & Efficient region & Peer & \multicolumn{2}{|c|}{ Mean PTE } & New efficient \\
\hline & count & Initial & New & region & to be removed & count & Initial & New & region \\
\hline Bishah & 7 & 0.937 & 0.956 & Hafr Al-baten & Bishah & 6 & 0.935 & 0.951 & \\
\hline Al-Ahsa & 6 & & 0.943 & Hail & Qaseem & 5 & & 0.939 & \\
\hline Jazan & 4 & & 0.936 & & Al-Ahsa & 4 & & 0.932 & \\
\hline Al-Qurayyat & 4 & & 0.941 & Hail & Asser & 4 & & 0.934 & \\
\hline Qunfudh & 4 & & 0.938 & & Riyadh & 3 & & 0.935 & Medinah \\
\hline Qaseem & 3 & & 0.942 & Taif & Al-Qurayyat & 3 & & 0.940 & Northern \\
\hline Al-Bahah & 3 & & 0.935 & & Eastern & 1 & & 0.931 & Tabouk \\
\hline \multirow[t]{2}{*}{ Asser } & 1 & & 0.934 & & Hail & 1 & & 0.931 & \\
\hline & & & & & Qunfudh & 1 & & 0.932 & \\
\hline \multicolumn{10}{|c|}{ Efficiency Scores: 2015} \\
\hline \multirow{2}{*}{$\begin{array}{c}\text { Efficient region } \\
\text { to be removed }\end{array}$} & Peer & \multicolumn{2}{|c|}{ Mean PTE } & New efficient & & & & & \\
\hline & count & Initial & New & region & & & & & \\
\hline Bishah & 10 & 0.913 & 0.939 & Tabouk & & & & & \\
\hline Qaseem & 6 & & 0.917 & Jazan & & & & & \\
\hline Asser & 5 & & 0.915 & Jazan & & & & & \\
\hline Al-Qurayyat & 5 & & 0.914 & & & & & & \\
\hline Riyadh & 4 & & 0.914 & Medinah & & & & & \\
\hline Al-Bahah & 3 & & 0.909 & Tabouk & & & & & \\
\hline Al-Ahsa & 2 & & 0.910 & & & & & & \\
\hline Qunfudh & 1 & & 0.909 & & & & & & \\
\hline
\end{tabular}




\section{Conclusion}

In this article we used the DEA approach to measure technical and scale efficiencies of all public hospitals in 20 regions in Saudi Arabia. The study shows that out of hospitals in 20 regions, eight (40 percent) indicate pure technical efficiency. The mean PTE of hospitals is 92.80 percent, indicating that on average 8.20 percent of the technical potential of hospitals is not being utilised. Therefore, this would imply that these hospitals have the potential to produce a 23.70 percent greater output whilst maintaining the same level of input. Al-Jouf is found to be the most inefficient region, its average efficiency score being 0.718 . This score indicates that hospitals in the Al-Jouf region could reduce their current input endowments by 28.2 percent. It is also noted that during the 5 -year period, most of the hospitals in the regions were operating under DRS. On average, there were 40 counts of DRS performance ( 40 percent), 37 counts of CRS ( 37 percent) and 23 counts of IRS ( 23 percent).

The results of CCR mode show that hospitals in only 3 regions (20 percent) are technically efficient, and therefore lie on the efficiency frontier (Qaseem, Bishah and Al-Qurayyat hospitals); the remaining 17 hospital regions ( 80 percent) are technically inefficient with an average total efficiency score of 0.899 . Among the inefficient hospitals, 8 regions have efficiency scores above the average efficiency. This reveals that hospitals must reduce their current input endowments by 10.1 percent. Jeddah' hospitals are the least efficient hospitals with a technical efficiency score of 0.742 . This score indicates that Jeddah hospitals could reduce their current input endowments by 25.8 percent.

The result of this paper could enable the health policy makers and hospitals managers to better understand the resources in the hospitals and to ensure that they are used effectively or not compared to other hospitals. The policy makers could also put forward some policies to stimulate hospitals to improve their performance. However, the conclusion on the efficiency of hospitals needs to be considered cautiously, as the results of this study are dependent upon the choice of the inputs and outputs.

The study gives valuable information on the efficiency of public hospitals in Saudi Arabia, however, it has some limitations such as excluding some variables that may have affected the efficiency score. As in some other DEA studies, this work does not include any quality variables associated with hospitals. Hence it does not offer any insight into the hospital quality or patient satisfaction levels. Inclusion of these variables would make the study more complete. Further research is clearly needed to eliminate the above deficiencies and to estimate technical efficiency at a more disaggregate level.

\section{References}

Abou El-Seoud, M. S. (2013). Measuring Efficiency of Reformed Public Hospitals in Saudi Arabia: An Application of Data Envelopment Analysis. International Journal of Economics and Management Sciences, 2(9), 44-53.

Al-Shayea, A. M. (2011). Measuring Hospitals' Units Efficiency: A Data Envelopment Analysis Approach. International Journal of Engineering \& Technology, 11(6), 7-14.

Applanaidu, S. D., Samsudin, S., Ali, J., Dash, U., \& Chik, A. R. (2014). Technical and Scale Efficiency of Public District Hospitals in Kedah, Malaysia A Data Envelopment Analysis (DEA). Journal of Health Management, 16(3), 327-335.

Asandului, L., Roman, M., \& Fatulescu, P. (2014). The Efficiency of Healthcare Systems in Europe: a Data Envelopment Analysis Approach. Procedia Economics and Finance, 10, 261-268.

Banker, R. D., Charnes, A., \& Cooper, W. W. (1984). Some Models for Estimating Technical and Scale Efficiencies in Data Envelopment Analysis. Management Science, 30(9), 1078-1092.

Barros, C. (2005). Evaluating the Efficiency of a Small Hotel Chain with a Malmquist Productivity Index. International Journal of Tourism Research, 7(3), 173-184.

Boussofiane, A., Dyson, R. G., \& Thanassoulis, E. (1991). Applied Data Envelopment Analysis. European Journal of Operational Research, 52, 1-15.

Bowlin, W. F. (1998). Measuring Performance: An Introduction to Data Envelopment Analysis (DEA). Journal of Cost Analysis, 7, 3-27.

Brown, H., Shelton, III., \& Pagán, J. A. (2006). Managed Care and the Scale Efficiency of US Hospitals. International Journal of Health Care Finance and Economics, 6(4), 278-289.

Burgess, J. F., \& Wilson, P. W. (1998). Variation in Inefficiency Among US Hospitals. INFOR, Canadian Journal of Operational Research and Information Processing, 36(3), 84-102. 
Charnes, A., Cooper, W. W., \& Rhodes, E. (1978). Measuring the Efficiency of Decision Making Units. European Journal of Operation Research, 2(6), 429-444.

Chen, A., Hwang, Y. C., \& Shao, B. (2005). Measurement and Sources of Overall and Input Inefficiencies: Evidences and Implications in Hospital Services. European Journal of Operational Research, 161(2), 447-468.

Chilingerian, J. A., \& Sherman, D. (2004). Health Care Applications from Hospitals to Physicians; from Productive Efficiency to Quality Frontiers. In Cooper, W W., Seiford, L. M., \& Zhu, J. (Eds.), Handbook on Data Envelopment Analysis. Boston: Kluwer Academic Publishers.

Dyson, R. G., Allen, R., Camanho, A. S., Podinovski, V. V., Sarrico, C. S., \& Shale, E. A. (2001). Pitfalls and Protocols in DEA. European Journal of Operational Research, 132, 245-259.

Emrouznejad, A., Parker, B. R., \& Tavares, G. (2008). Evaluation of Research in Efficiency and Productivity: A Survey and Analysis of the First 30 Years of Scholarly Literature in DEA. Socio-Economic Planning Sciences, 42(3), 151-157.

Ferrier, G. D., Rosko, M. D., \& Valdmanis, V. G. (2006). Analysis of Uncompensated Hospital Care Using a DEA Model of Output Congestion. Health Care Management Science, 9(2), 181-188.

Gok, M. S., \& Sezen, B. (2011). Analyzing The Efficiencies of Hospitals: An Application of Data Envelopment Analysis. Journal of Global Strategic Management, 10, 137-46.

Golany, B., \& Roll, Y. (1989). An Application Procedure for DEA. Omega, 17, 237-250.

Grosskopf, S., \& Valdmanis, V. (1987). Measuring Hospital Performance: A Non-Parametric Approach. Journal of Health Economics, 6(2), 89-107.

Grosskopf, S., \& Valdmanis, V. (1993). Evaluating Hospital Performance with Case-mix Adjusted Outputs. Medical Care, 31, 525-532.

Harris, J., Ozgen, H., \& Ozcan, Y. A. (2000). Do Mergers Enhance the Performance of Hospital Efficiency?. The Journal of Operational Research Society, 51(7), 801.

Harrison, J. P., \& Sexton, C. (2006). The Improving Efficiency Frontier of Religious Not-For-Profit Hospitals. Hospital Topics, 84(1), 2-10.

Harrison, Jeffrey P., Coppola, M. Nicholas and Wakefield, Mark (2004). Efficiency of Federal Hospitals in the United States. Journal of Medical Systems, 28(5), 411-422.

Hollingsworth, B., Dawson, P. J., \& Maniadakis, N. (1999). Efficiency Measurement of Health Care: A Review of Non-parametric Methods and Applications. Health Care Management Science, 2, 161-72.

Hollingsworth, B. (2003). Non-parametric and Parametric Applications Measuring Efficiency in Health Care. Health Care Management Science, 6(4), 203-218.

Hollingsworth, B. (2008). The Measurement of Efficiency and Productivity of Health Care Delivery. Health Economics, 17(10), 1107-1128.

Kazley, A. S., \& Ozcan, Y. A. (2009). Electronic Medical Record Use and Efficiency: A DEA and Windows Analysis of Hospitals. Socio- Economic Planning Sciences, 43(3), 209.

Ministry of Health-Saudi Arabia. (2010, 2011, 2013, 2014, 2015). Health Statistical Year Book, Riyadh, Ministry of Health.

Mogha, S. K., Yadav, S. P., \& Singh, S. P. (2012). Performance Evaluation of Indian Private Hospitals Using DEA Approach with Sensitivity Analysis. International Journal of Advances in management and Economics, 1(2), 1-12.

O'Neill, L., Rauner, M., Heidenberger, K., \& Karus, M. (2008). A Cross-national Comparison and Taxonomy of DEA-based Hospital Efficiency Studies. Socio-Economic Planning Sciences, 42(3), 158-189.

Perez, G., Coskunoglu, O., \& Moore, A. (1998). Data Envelopment Analysis as a Tool to Evaluate Efficiency of Army Real Property Management Activities (RPMA) Spending. U.S. Army Corps of Engineers Construction Engineering Research Laboratory.

Prakash, V., \& Annapoorni D. (2015), Performance Evaluation of Public Hospitals in Tamil Nadu DEA Approach. Journal of Health Management, 17(4), 417-424.

Shahhoseini, R., Tofighi, S., Jaafaripooyan, E., \& Safiaryan, R. (2011). Efficiency Measurement in Developing 
Countries: Application of Data Envelopment Analysis for Iranian Hospitals. Health Services Management Research, (24), 75-80.

Shim, W. (2000). Assessing Technical Efficiency of Research Libraries. In D.E. Williams \& E.D. Garten (Eds), Advances in Library Administration and Organization, 17, 243-339.

Sikka, V., Luke, R. D., Ozcn, Sikka, V., Luke, R. D., \& Ozcn, Y. A. (2009). The Efficiency of Hospital-based Cluster: Evaluating System Performance Using Data Envelopment Analysis. Health Care Management Review, 34(3), 251.

Simar, L., \& Wilson, P. W. (1998). Sensitivity Analysis of Efficiency Scores: How to Bootstrap in Nonparametric Frontier Models. Management Science, 44(1), 49-61.

Tigga, N. S., \& Mishra, U. S. (2015). On Measuring Technical Efficiency of the Health System in India: An Application of Data Envelopment Analysis. Journal of Health Management, 17(3), 285-298.

Umakant, D., Vaishnavi, S. D., Muraleedharan, V. R., \& Debashis, A. (2007). Benchmarking the Performance of Public Hospitals in Tamil Nadu: An Application of Data Envelopment Analysis. Journal of Health Management, 9(1), 59-74.

Valdmanis, V. (1992). Sensitivity Analysis for DEA Models: An Empirical Example Using Public Versus NFP Hospitals. Journal of Public Economics, 48,185-205.

Worthington, A. (2004). Frontier Efficiency Measurement in Health Care: A Review of Empirical Techniques and Selected Applications. Medical Care Research and Review, 61(2), 135-170.

\section{Copyrights}

Copyright for this article is retained by the author(s), with first publication rights granted to the journal.

This is an open-access article distributed under the terms and conditions of the Creative Commons Attribution license (http://creativecommons.org/licenses/by/4.0/). 